\title{
SUBMENTAL INTUBATION - A NEW APPROACH IN PANFACIAL TRAUMA
}

Monika Gandhi' ${ }^{1}$ B.K. Ved ${ }^{2}$

\section{HOW TO CITE THIS ARTICLE:}

Monika Gandhi, BK Ved. "Submental intubation - a new approach in panfacial trauma". Journal of Evolution of Medical and Dental Sciences 2013; Vol2, Issue 36, September 9; Page: 6954-6957.

ABSTRACT: The submental route for endotracheal intubation is an alternative to nasal intubation or tracheostomy in the surgical management of patients with complex cranio-maxillofacial injuries. The critical indication for submental intubation is the requirement for intraoperative maxillamandibular fixation (MMF) in the presence of injuries that preclude nasal intubation and in a situation where a tracheostomy is not otherwise required. MMF to re-establish dental occlusion is essential for a normal functional result in dentate patients with fractures involving alveolar segments of the jaws. However, MMF precludes orotracheal intubation. Nasotracheal intubation is often used but is contraindicated in the presence of skull base fractures and will interfere with the access to certain fracture types. A tracheostomy has a high potential complication rate and in many patients, an alternative to the oral airway is not required beyond the perioperative period. Submental intubation is a simple and useful technique with low morbidity in selected cases of cranio-maxillofacial trauma.

KEYWORDS: Maxillofacial trauma, Submental endotracheal intubation.

INTRODUCTION: Surgical repair of maxillofacial trauma requires modification of the standard anaesthesia technique. Nasal endotracheal intubation is often contraindicated in the presence of fracture of base of the skull ${ }^{1}$. Comminuted midfacial fractures cause physical obstruction to the passage of nasotracheal tube ${ }^{2}$. Further, the presence of nasotracheal tube can interfere with surgical reconstruction of fractures of the naso-orbital ethmoid (NOE) complex ${ }^{3}$. Surgical reconstruction often involves maxillo-mandibular fixation in the intraoperative period to restore patient's dental occlusion. This precludes the use of oral endotracheal intubation in such cases. In these conditions tracheostomy may be indicated but it carries a significant morbidity ${ }^{4-6}$. Submental endotracheal intubation has been described as a useful alternative to tracheostomy with minimal complications in these conditions ${ }^{7-10}$.

CASE REPORT: A 30 year old male was referred to our institute from a Govt. dental hospital. History revealed patient had road traffic accident three days before referral to the institute. At the time of mishap he had nasal bleeding. Visible deformity of facial skeleton included depressed right zygoma. Mouth opening was more than $3 \mathrm{cms}$. Malampatti score I dental malocclusion was evident. Radiological examination showed fracture zygomatic arch, lateral margin right orbit fracture, Lefort II and III fracture on right side with comminution at right frontonasal junction.

The patients airway options were limited. Nasotracheal intubation was clearly contraindicated because of Lefort fractures. Oral intubation was precluded because of surgical prerequisite of checking dental occlusion. Submental intubation was opted against tracheostomy.

Patient was kept fasting for 8 hours preoperatively. Inj. Glycopyrrolate $0.2 \mathrm{mg}$ Intramuscular given before surgery. Preoxygenation with $100 \% \mathrm{O}_{2}$ given for 5 minutes. Induction of anaesthesia done with injection Propofol $2-3 \mathrm{mg} / \mathrm{kg}$ intravenously. Ability to mask ventilate was 
confirmed. Injection Succinylcholine $2 \mathrm{mg} / \mathrm{kg}$ given intravenously. After direct laryngoscopy, oral endotracheal intubation done with 38G flexo-metallic tube. Throat packing done. Anaesthesia was maintained with $\mathrm{O}_{2}: \mathrm{N}_{2} \mathrm{O}=50: 50$ and Inj Atracurium $0.3 \mathrm{mg} / \mathrm{kg}$. Analgesia was maintained with injection Fentanyl Citrate $2 \mu \mathrm{g} / \mathrm{kg}$ intravenously. Now $3 \mathrm{~cm}$ incision was made in the right submental region by the surgeon. It was extended intraorally. The pilot balloon was grasped by the artery forceps and was pulled out gently with the connecting tube, taking care not to damage it. Endotracheal tube was disconnected from the non-rebreathing valve of breathing circuit. Connector was removed from the tube. Now by the pulling the pilot tube, while stabilizing the tracheal end of tube by Magill's forceps, proximal end of tube was removed out. Connector and breathing system were attached again. Pulse oximeter and Electrocardiography showed no changes throughout the procedure. After reattachment the position of the tube was confirmed by chest auscultation. Tube was wrapped with gauze, fixed with sutures taking care not to damage the tube. Now the surgeon could easily access both nasal and oral fields.

Throat packing gave extra margin of safety against aspiration of blood. Surgery went uneventfully for a duration of 3 hours. After the end of surgery, submental intubation was converted to oral intubation by pulling pilot tube into oral cavity, submental wound was closed.

Reversal of neuromuscular blockade was done uneventfully by injection Glycopyrrolate 0.01 $\mathrm{mg} / \mathrm{kg}$ and injection Neostigmine $0.05 \mathrm{mg} / \mathrm{kg}$ intravenously. After checking adequate recovery from neuromuscular blockade, patient was extubated.

DISCUSSION: Altemir, in 1986, first described the submental route for endotracheal intubation7. This technique provided a secure airway, an unobstructed intraoral surgical field and allowed maxilla-mandibular fixation while avoiding the drawbacks and complications of nasotracheal intubation and tracheostomy ${ }^{8}$. Nasotracheal intubation is not possible in the presence of fractures of nasal skeleton, skull base fractures and cerebrospinal fluid rhinorrhoea. Any attempt towards nasotracheal intubation can lead to passage of tube into the cranium, meningitis, sepsis, sinusitis and epistaxis 1,11,12. Our patient had epistaxis and fracture of nasal bone; all of which precluded nasotracheal intubation.

Tracheostomy, an alternate technique preferred by some surgeons and anesthesiologists, is associated with complications like haemorrhage, subcutaneous emphysema, pneumomediastinum, pneumothorax, recurrent laryngeal nerve damage, stomal and respiratory tract infection, tracheal stenosis, tracheal erosions, dysphagia, problems with decannulation and excessive scarring ${ }^{4-6}$. Submental endotracheal intubation is not free of adverse events and complications. Adverse events can occur while the endotracheal tube is passed through the incision from interior to exterior. It may be difficult to pass the tube through the incision or reattaching the connector to endotracheal tube. These adverse events can be overcome by Green and Moore's modification to the original technique. They used two endotracheal tubes in their technique. They first secured the airway with conventionally placed oral tracheal tube. Reinforced endotracheal tube was then drawn in from exterior to interior through the submental incision. The original oral tube was withdrawn and reinforced tube substituted. At the end of the procedure, the process may be reversed. This technique is also useful when manufacturer's design specifically prevents the removal of tube connector ${ }^{13}$. However, grasping and drawing in the tracheal end of the endotracheal tube can damage the cuff. Maclnnis and Baig reported that their experience with standard technique as 


\section{CASE REPORT}

described by Altemir was less than satisfactory because of bleeding, difficult tube passage and sublingual gland involvement. Instead of slight lateral exit wound sub mentally, they modified the technique to strict midline approach in 15 patients with satisfactory results ${ }^{14}$.

However, we followed the original technique and had no difficulty in passing the tube through the incision, the endotracheal tube connector could be easily detached and reattached and there was no bleeding. Accidental extubation, tube obstruction and damaged tube (leaking cuff) are more difficult to manage in submental route. Endotracheal tube exchanger has been used successfully to replace the damaged tracheal tube by the submental approach ${ }^{15}$. Other potential complications are superficial infection of the submental wound, trauma to submandibular and sublingual glands or ducts, damage to lingual nerve, oro-cutaneous fistula and hypertrophic scar ${ }^{7}$. However, no complication occurred in our patient. Perioperative antibiotic cover, good oral hygiene and not so tight closure of submental incision resulted in prevention of infectious complications. Submental tracheal tube has been kept in situ for up to two to three days postoperatively. In such cases, it is mandatory that an immediate access to oral airway is ensured at all times and maxillamandibular fixation should not be used until after extubation and confirmation of secure airway ${ }^{8,9}$.

In our patient we did not keep the endotracheal tube in situ as there was no airway oedema. Therefore, in selected group of patients with severe maxillofacial trauma, submental endotracheal intubation is a useful and relatively harmless alternative to tracheostomy for securing airway.

\section{REFERENCES:}

1. Muzzi DA, Losasso TJ, Cucchiara RF. Complication from a nasopharyngeal airway in a patient with a basilar skull fracture. Anesthesiology 1991; 74: 366-8.

2. Zmyslowski WP, Maloney PL. Naso-tracheal intubation in the presence of facial fractures. JAMA 1989; 262: 1327-8.

3. Haug RH, Indresano AT. Management of maxillary fractures. In: Peterson LJ, ed. Principles of oral and maxillofacial surgery. Philadelphia: JB Lippincott, 1992: 469-88.

4. Chew JY, Cantrell RW. Tracheostomy, complications and their management. Arch Otolaryngol 1972; 96: 538-45.

5. Walker DG. Complications of tracheostomy: their prevention and treatment. J Oral Surg 1973; 31: 480-2.

6. Stauffer JL, Olson DE, Petty TL. Complications and consequences of endotracheal intubation and tracheotomy. AmJ Med 1981; 70: 65-76.

7. Altemir FH. The submental route for endotracheal intubation: a new technique. J Maxillofac Surg 1986; 14: 64-5.

8. Caron G, Paquin R, Lessard MR, Trepanier CA and Landry PE. Submental endotracheal intubation: an alternative to tracheotomy in patients with midfacial and panfacial fractures. J Trauma 2000; 48: 235-40.

9. Gordon NC, Tolstunov L. Submental approach to oro-endotracheal intubation in patient with midfacial fractures. Oral Surg Oral Med Oral Pathol Oral Radiol Endod 1995; 79: 269-72.

10. Chandu A, Smith ACH, Gebert R. Submental intubation: an alternative to short-term tracheostomy. Anaesth Intensive Care 2000; 28: 193-5.

11. Seebacher J, Nozik D, Mathieu A. Inadvertent intracranial introduction of a nasogastric tube, a complication of severe maxillofacial trauma. Anesthesiology 1975; 42: 100-2. 
12. Stone DJ, Bogdonoff DL. Airway considerations in the management of patients requiring long-term endotracheal intubation. Anesth Analg 1972; 74: 276-87.

13. Green JD, Moore UJ. A modification of sub-mental intubation. Br J Anaesth 1996; 77: 789-91.

14. Maclnnis E, Baig M. A modified submental approach for oral endotracheal intubation. Int J Oral Maxillofac Surg 1999; 28: 344-6.

15. Drolet P, Girard M, Poirier J, Grenier Y. Facilitating submental endotracheal intubation with an endotracheal tube exchanger. Anesth Analg 2000; 90: 222-3.

\section{AUTHORS:}

1. Monika Gandhi

2. B.K. Ved

\section{PARTICULARS OF CONTRIBUTORS:}

1. Associate Professor, Department of Anaesthesiology, M.G.M. Medical College, Indore (M.P.)

2. Professor, Department of Anaesthesiology, M.G.M. Medical College, Indore (M.P.)

\section{NAME ADDRESS EMAIL ID OF THE}

\section{CORRESPONDING AUTHOR:}

Dr. Monika Gandhi,

91/3, Vallabh Nagar,

Kalptaru,

Indore, M.P., PIN - 452003.

Email-drmonikagandhi2911@gmail.com

Date of Submission: 11/08/2013.

Date of Peer Review: 12/08/2013.

Date of Acceptance: 02/09/2013.

Date of Publishing: 05/09/2013 